\title{
Teaching-Learning Mathematics in a Virtual Environment. Empirical Evidence in Scenarios of Higher Education
}

\author{
Lizzeth Aurora Navarro-Ibarra ${ }^{a}$, Omar Cuevas Salazara, Julia Xochitl \\ Peralta García ${ }^{a}$ and Julio César Ansaldo Leyva ${ }^{a}$
}

anstituto Tecnologico de Sonora, MÉXico

\begin{abstract}
Tomorrow's citizens must have the basic tools necessary for total development. Among these tools are mathematics and technology. In the present research we propose taking advantage of technology for teaching-learning mathematics. The objective is to determine whether a Virtual Leaning Environment (VLE) for mathematics can diminish the indexes of failing and improve academic performance. The study has a pretest-posttest quasi-experimental design with a nonequivalent control group. The participants are engineering students at the Instituto Tecnológico de Sonora (Technological Institute of Sonora), Mexico. 68 students participated in the experimental group and 60 in the control group. The experimental group studied academic subjects using VLE while the control group studied in a classroom with a professor who explained the concepts. The results show significant difference in the index of failing and academic performance. The implementation of VLE for mathematics would be beneficial to the extent that it is designed using pedagogical practices within a context supported by technology.
\end{abstract}

KEYWORDS

Technology, learning environment, Mathematics, first year university student
ARTICLE HISTORY

Received 11 September 2016

Revised 17 November 2016 Accepted 27 February 2017

\section{Introduction}

Education and formal training should provide all individuals with competence which leads them to personal accomplishment and development, social inclusion, active citizenship and employment. Among the abilities which should be attained according to the European Commission (2016) are literacy, arithmetic, science and foreign languages, as well as digital competence, business skills, critical thinking, problem solving, learning to learn and financial literacy. Besides, an early command of these skills allows for better forming the

\section{CORRESPONDENCE Lizzeth A. Navarro-Ibarra lizzeth.navarro@gmail.com}

(C) 2017 Lizzeth A. Navarro-lbarra et al.

Open Access terms of the Creative Commons Attribution 4.0 International License apply. The license permits unrestricted use, distribution, and reproduction in any medium, on the condition that users give exact credit to the original author(s) and the source, provide a link to the Creative Commons license, and indicate if they made any changes. (http://creativecommons.org/licenses/by/4.0/) 
complex competencies needed for promoting creativity and innovation which in the long run assure a prosperous life for a person in the workplace as well as in a rapidly changing society.

Education lacks a general consensus on approaches to teaching and learning which would lead to improved performance. There is also the need for joint commitment between educational authorities and teachers. These aspects make it impossible for any effort to innovate, reform or change education to produce a lasting effect on students' academic performance (Bain \& Weston, 2012).

The Organization for Economic Cooperation and Development (OECD) groups together 35 countries and its purpose it to promote policies which improve the economic and social wellbeing of the world (OECD, 2017). Based on this premise, the Program for International Student Assessment (PISA) was created. Its objective is to every three years evaluate the students who are at the end of their obligatory education. The results of these evaluations allow for determining whether 15 year olds have acquired the basic knowledge and skills in science, mathematics and reading that assure their full participation in higher education (PISA, 2017).

The results of PISA given in 2015 indicated that Mexican students' performance is below the average of the countries of the OECD. In mathematics students achieved an average of 408 points; 490 being the average for the OECD. While between 2003 and 2015 performance in mathematics in Mexico has increased on average 5 points every three years, in 2015 the points obtained are below what was achieved in 2009 (419 points). An average of $23 \%$ of the students in participating countries does not obtain the basic level of competence. However in Mexico the percentage is much greater (57\%), a situation which has not changed since 2003. With reference to the level of excellence, the average indicates that $10.7 \%$ of the students in OECD countries reach this category, while in Mexico only $0.3 \%$ do and this number decreased in relation to 2006, 2009 and 2012 (OECD, 2016).

In Mexico by way of the Plan Nacional para la Evaluación de los Aprendizajes (National Plan for the Evaluation of Learning) (Planea) the Evaluación del Logro Referida al Sistema Educativo Nacional (Evaluation of Achievement Referring to the National Education System) (ELSEN) was given to students in sixth grade of primary school and third grade of secondary in 2015. The exam evaluates mathematics, language and communication and classifies students into four levels of achievement: insufficient, bare necessities, satisfactory and outstanding (PLANEA, 2017). At the secondary school level in mathematics the data shows that approximately half of the students are placed in the level of insufficient (51.3\% in 2015 and $49.2 \%$ in 2016), showing a slight improvement in the second year. We find $30 \%$ of students in 2016 at the level "bare necessities," an improvement of one tenth of one percent with respect to 2015. We see an increase of 2 percent in the satisfactory level from one year to the next $(12.4 \%$ and $14.4 \%)$, this being the category with the biggest change. However, the number of results in the outstanding level decreased $.1 \%$ in 2016 , reaching 6.3\% (PLANEA, 2016).

The use of technology with educational aims has the potential of increasing deep learning. However, this depends on how it is used for specific 
purposes. Besides, technology should be integrated into pedagogy in order to make activities more attractive, efficient, technologically generalized and centered on problem solving in real life situations (Fullan \& Langworthy, 2013).

The expectative of Information and Communication Technology (ICT) in the area of mathematics, is to design new cognitive measurements with interactive focuses in order to increase the quality of learning and school performance. In this way mathematical formation is formed by way of discovery, evaluation and creation, without discarding conceptual understanding, the development of skills for mathematical processes and their applications (Bravo, 2012).

An analysis of 20 studies carried out by Zakaria and Khalid (2016) determined that the benefits of incorporating ICT into teaching mathematics are multiple. Among the advantages of a Virtual Learning Environment (VLE) are: increasing students' interest in learning mathematics, improving academic performance, promoting permanent learning, allowing for positive interactive relations and supporting constructivist learning.

Now then, in the face of the possibilities ICT offers for teaching and learning mathematics we pose our first question for this research: What effect does the implementation of a Virtual Learning Environment for learning mathematics have on the index of the number of students who fail mathematics? At the same time the second question to be answered by this research emerges: What effect does the implementation of VLE for learning mathematics have on students' academic performance? been set:

In order to answer these research questions the following objectives have

Objective 1: Determine the effect implementing a Virtual Learning Environment for teaching mathematics has on the index of student's failing mathematics.

Objective 2: Determine the effect implementing a Virtual Learning Environment for teaching mathematics has on students' academic performance.

\section{Revision of Literature}

In today's society leaning is permanent; it is not only acquired through formal means, but also in non-formal or informal ways. However, not all students have the skills necessary for autonomous studying and therefore we must promote the development of these skills so that students can attain the knowledge they need. Self-regulated learning, self-evaluation and actions for modifying study habits promote students' active and critical participation in decision-making related to their education, which will result in the formation of more meaningful environments (Cabero, 2013).

Virtual learning is a process of personal reconstruction of a content which is carried out in function of and based on the cognitive structure of learning. Among the elements which make up this structure are basic cognitive skills, specific knowledge of an area, learning strategies, meta-cognitive abilities and self-regulation, affective and motivational factors goals and expectations. All of these elements and the way a student utilizes them can lead to quality learning (Onrubia, 2016). 
The change of paradigm represented by virtual learning is not only a change for students but also for all of those involved in the educational system. This is why teachers, administrators, technical and support staff as well as the institution itself find themselves faced with a new and different form of teaching-learning in which the ambit is no longer a closed system such as a classroom. In order to work for various kinds of students, the development of VLE requires an effort of migrating from a closed system to a new reality. This demands constant up-dating of subjects which arise related to virtual learning in order to incorporate them during the design of VLEs (Khan, 2016).

The challenge in virtual learning as in any other teaching system is to achieve efficacy. This is achieved when lessons which are compatible with the processes of human learning are developed. Moreover, it must be taken into account that ICT has the ability to provide much more sensorial data than a person's nervous system can assimilate. Learning may decrease if the audio and visual elements used in a lesson interfere with human cognition (Clark \& Mayer, 2016).

Virtual leaning environments should be spaces for teaching and producing learning which are pedagogically modeled and integrated with various components such as: technological platform, activities and material, which all together have the objective of generating learning. In turn, interaction of the community by way of technological tools enriches the quality of learning (Silva, 2011).

Generally speaking according to Clark and Mayer (2016) the VLE should have one or more of the following characteristics: students can control their progress throughout a lesson; the methods for achieving commitment create adequate psychological processing; the graphs and vocabulary in each lesson correspond to the level of learning maturity of the student; realistic settings are used to create the learning context.

In the teaching of mathematics a VLE is a means by which ICT facilitates pedagogical communication between the teacher and the student during the teaching-learning process, promoting the self-construction of the educable subject. The design of a VLE should include these five aspects: knowledge (design of interactive digital content with pedagogical perspective), collaboration (student-student, student-teacher and teacher-teacher interaction), consulting (both synchronous and asynchronous), experimentation (simulation) and management (homework, evaluation and follow-up), all of this in order for technology to stimulate the required learning (Bravo, 2012).

\section{Methodology}

The present study has a quasi-experimental design with nonequivalent control group using pretests and posttests. A didactic proposal in a VLE was created and the study was carried out with university students from the Instituto Tecnológico de Sonora (Technological Institute of Sonora) located in Northwestern Mexico. The participants were not chosen at random, but rather were already enrolled in a group of Calculus I for Engineers. Two groups were chosen, one experimental and the other the control group. The experimental group was made up of 68 students and the control group of 60 students. For the experimental group the subject was taught using VLE designed for this purpose. 
For the control group the teaching was traditional, that is, in a classroom where the teacher explained the lesson and the students were the receptors.

The VLE was built with the objective of learning of the linear model. The digital resources were developed with free software available on Internet. The linear model in this didactic proposal consists of two subjects. Subject I refers to the study of uniform change and subject II is about calculus of the approximate value of accumulated change in keeping with Salinas et al.'s proposal (2012).

The instrument used to identify the knowledge acquired by the students was made with open-ended questions on the mathematical concepts studies and given as a pretest and posttest to both the experimental and control groups. The exam was made up of nine questions. The linear model was evaluated using the study of uniform change with five questions and the calculus of approximate value of accumulated change with four questions. The grading scale at the university is 0 through 10 , with the lowest passing grade being seven. The exam was given face-to-face and on paper.

To create the VLE the WIX platform which is used for creating free Websites was employed. It is easy to use since it requires no technical knowledge and is compatible with search engines. The site allows for the use of templates as support in the design, but in the development of this virtual learning environment they were not used. The design of the environment was elaborated in accordance with the activities of the proposal. In turn, the platform allows for moving through the content with a menu at the top and buttons which provide the options recommended for the student.

The environment contains sections where information and activities are provided for the student and with which they can interact and receive immediate feedback. The structure of the Web page consists of a general introduction, map of activities, introduction to the subject and objective, lessons for learning and self-evaluations for each lesson. Moreover there is a summary of the subject, conceptual map, and basic bibliography and consulting. There is in addition a section called "to know more" in which You Tube videos are suggested with input on the subject being studied.

The subjects were developed using lessons that are videos with images and audio in which teachers explain a problem of a situation of daily life and lead to solving the situation. The subject of uniform change is analyzed in four lessons. The first three lessons are problematic situations and the fourth is the formal context. Lesson 1 is about a car that is travelling along a straight highway at a constant speed. The second lesson is about the change in constant temperature of a pot of water on a burner. The change in temperature depending on the altitude of a mountain is seen in lesson 3. The integration of the first three lessons takes place in the fourth 4 lesson where the formalization of the concept of linear function is made.

The calculation of the approximate value of accumulated change consists of three lessons. In the first lesson the problem of the car travelling along a straight highway is once again faced, but this time the speed is no longer constant; it is determined by a non-linear function. In lesson 2 the same problem is dealt with but with the use of a technological resource (a spreadsheet), which 
allows for smaller increases. The third lesson is about a round tank which is filling up with water with a non-linear rate of change.

For both subjects there are self-evaluation exercises for each lesson. These activities are interactive; the student solves the problem and immediately receives feedback. The self-evaluations were designed for each lesson in order to help the student practice what he has studied. Due to the differences in themes I and II, the activities of self-evaluation were designed using different software. In all of the self-evaluations the student interacts with the application and immediately receives the results. The user may evaluate their answer and try again or ask for an explanation with the correct calculation, if need be.

In theme I the self-evaluations were designed using the mathematical software GeoGebra, which has the characteristics of being dynamic and opensourced. The activities consist of a text, images, capture checkbox and buttons to be used to carry out actions. Interactivity with the application and immediate feedback were carried out using the layers in which the objects are placed. The progress and regression within the activity were achieved using buttons.

The self-evaluations of theme II, on the calculation of the approximate valued of accumulated change, was developed using Active Presenter software whose objective was to create guides. This software allows one to record the movements on the screen, easing its edition and selection of sequences which would explain in detail the points of interest. At the same time one may add audio for each slide separately in order to explain what is being seen on the screen.

With this application one can also create evaluations with entrance checkboxes and selection of multiple choice answers, among other things. Feedback is immediate and may be structured with images and mathematical calculations, as well as text. Scrolling through slides or sequences may be controlled by timing or using buttons which are programmed to carry out a certain action. The evaluation section may be set up so that a student must answer a question before continuing on to the following section, and a sign indicating this can be shown.

In each lesson before beginning with the video, an estimate of the time needed for the student to study the lesson and do the self-evaluation is given. The amount of time given takes into account leeway for stopping the video and returning to watch a specific point. In the same way, in the self-evaluations the user may return and repeat an exercise as many times as he needs in order to fully understand the concept.

The homework and evaluation of the subjects are also contemplated in different sections. Turning in homework was designed keeping in mind making it easy for the students and seeking immediate revision and feedback. The tool used was the formula of Google linked to an electronic page on Google Drive. It is also necessary to install a complement called Easy Quiz used to automatically send the grade and feedback to each student.

The evaluation was developed in a similar way as the homework section. The only difference being that there is no option to previously see the problems to be solved. In other words, there is no file with a list of the problems to 
download. In the evaluation section the procedure to be followed is described and a "pencil" icon is presented at the beginning of the evaluation.

As with homework, the evaluation was designed for automatic grading and delivery to the student's e-mail along with feedback for all problems. This is why the Google forms were used along with the electronic sheet of Google Drive and the Easy Quiz complement used to administer the sending of grades and feedback.

With respect to communication, a section to carry it out asynchronously between student and teacher was designed. In the section called "Contact" the student may send messages to the teacher with questions about the subject, about the page or technical problems. The messages sent by the students reach the teacher's e-mail and using the same media the teacher may answer the student's questions. The teacher's e-mail is also given as an option for the student to send messages directly from their own e-mail. There is also a bulletin board where announcements may be published for all users to see.

Following you will find a description of the procedure used for the present research.

1. A time limit was set for teaching the subjects seen in the VLE, 7 hours. This length of time was respected for both groups. In the experimental group the students were in a classroom with computers and internet available for each participant, assuring surfing in the VLE. Besides this, the VLE could be accessed from any device with an internet connection 24 hours a day during the period of the study.

2. The application of the pretest and posttest that consisted of an exam of knowledge of the two subjects which made up the study was made in person and on paper. The pretest was given before beginning the VLE in the experimental group and using traditional instruction for the control group. The posttest was given to both groups upon finishing teaching the subjects.

3 . The instrument for measuring the acquisition of knowledge as pretest and posttest of both groups was graded.

4. The information was analyzed using the statistical program "Statistical Package for the Social Sciences" (SPSS). The Wilcoxon signed-rank test for dependent groups and the Mann-Whitney $U$ test for independent groups were carried out. Similarly the Z-score for differences in proportions was obtained.

\section{Results}

\section{First Objective}

The first objective established was to determine the effect on the failure index of the implementation of a VLE for learning mathematics in a study group compared to traditional teaching.

The exam of knowledge given as a posttest to the experimental and control groups determined the number of students who passed and failed. Table 1 describes the number of students who passed and failed for the experimental and control groups as well as the respective percentage. In the experimental group $61.76 \%$ failed while in the control group $85 \%$ failed. 
In order to determine whether there was a significant difference between the percentages of those who failed in the experimental and control groups, the $\mathrm{Z}$-score was calculated for the difference in proportions of the two groups. The significance level was set at $0.05 \%$ with a critical $\mathrm{z}$ value $= \pm 1.96$ with bilateral contrast.

Table 1. Frequencies and percentages of students who passed and failed in the experimental and control groups

\begin{tabular}{lcccc}
\hline & \multicolumn{2}{c}{ Experimental Group } & \multicolumn{2}{l}{ Control Group } \\
\cline { 2 - 5 } Students & $\mathrm{N}$ & $\%$ & $\mathrm{~N}$ & $\%$ \\
\hline Failed & 42 & 61.76 & 51 & 85.00 \\
Passed & 26 & 38.24 & 9 & 15.00 \\
Total & 68 & 100 & 60 & 100 \\
\hline
\end{tabular}

The Z-score was -3.1061, in the failed area. This indicated that the percentage of those who failed is different between the experimental and groups. The data concentrated in Table 1 show that the percentage of students who failed is $23.24 \%$ lower for the experimental group than for the control group.

\section{Second Objective}

The second objective is to determine the academic performance attained in learning mathematics in a Virtual Environment. The performance was evaluated by giving a pretest and posttest of knowledge to both the experimental and control groups. The instrument has a scale of zero to ten. Table 2 concentrates the descriptive statistics obtained on the pretest and posttest for the experimental and control groups.

Table 2. Descriptive statistics for the exam of knowledge for the experimental and control groups

\begin{tabular}{lcccccc}
\hline Group & & $\mathrm{N}$ & Mean & $\begin{array}{c}\text { Standard } \\
\text { Deviation }\end{array}$ & Minimum & Maximum \\
\hline Experimental & Pretest & 68 & 1.822 & 1.9527 & 0.0 & 7.22 \\
& Posttest & & 5.727 & 3.0463 & 0.0 & 10.00 \\
Control & Pretest & 60 & 1.574 & 2.0665 & 0.0 & 8.89 \\
& Posttest & & 3.935 & 2.9278 & 0.0 & 10.00 \\
\hline
\end{tabular}

The distribution of data is non-parametric and intra- and inter-group statistical tests were carried out following the procedure used by Cabero and LLorente (2006). For intra-group analysis the Wilcoxon signed-rank test was used and for inter-group analysis the Mann-Whitney U test was used.

In Table 3 the parameters obtained with the Wilcoxon signed-rank test for the experimental group are presented. The significance is zero, which indicates that there was a difference between the pretest and the posttest. The sum of 
positive ranges (1827.50) is greater than the sum of negative ranges (2.50) therefore the posttest is greater than the pretest. Thus, it may be said that the academic performance improved for the experimental group following the intervention.

Table 3. Test of the ranges with Wilcoxon signed-rank for the experimental group

\begin{tabular}{llllll}
\hline & N & $\begin{array}{l}\text { Average } \\
\text { Range }\end{array}$ & $\begin{array}{l}\text { Sum } \\
\text { Ranges }\end{array}$ & Sig. \\
\hline Negative Ranges (Posttest < Pretest) & 1 & 2.50 & 2.50 & -6.728 & 0.00 \\
Positive Ranges (Posttest > Pretest) & 59 & 30.97 & 1827.50 & & \\
Ties (Posttest = Pretest) & 8 & & & \\
Total & 68 & & & \\
\hline
\end{tabular}

Note: $\mathrm{Z}$ score based on negative ranges.

Table 4 concentrates the results of the Wilcoxon signed-rank test for the control group. The significant value is zero, which confirms a difference between the pretest and posttest. The sum of positive ranges (960.00) is greater than the sum of negative ranges (30.00) and therefore the posttest is greater than the pretest. The posttest has a sum of higher ranges greater than the pretest, which corroborates that academic performance also increases with teaching in a traditional classroom without virtual resources.

Table 4. Test of ranges with Wilcoxon signed-rank for the control group

\begin{tabular}{llllll}
\hline & N & $\begin{array}{l}\text { Average } \\
\text { Range }\end{array}$ & $\begin{array}{l}\text { Sum of } \\
\text { Ranges }\end{array}$ & Z & Sig. \\
\hline Negative Ranges (Posttest < Pretest) & 4 & 7.50 & 30.00 & -5.449 & 0.00 \\
Positive Ranges (Posttest > Pretest) & 40 & 24.00 & 960.00 & & \\
Ties (Posttest = Pretest) & 16 & & & \\
Total & 60 & & & \\
\hline
\end{tabular}

Note: $\mathrm{Z}$ score based on negative ranges.

The analysis between the experimental and control groups was done with a test for independent groups. The Mann-Whitney U test was used (see Table 5).

Table 5. Mann-Whitney $U$ test for the experimental and control groups

\begin{tabular}{lllll}
\hline & Group & N & Average Range & Sum of Ranges \\
\hline Pretest & Experimental & 68 & 67.47 & 4588 \\
& Control & 60 & 61.13 & 3668 \\
\hline
\end{tabular}




\begin{tabular}{|c|c|c|c|c|}
\hline \multirow[t]{2}{*}{ Posttest } & Experimental & 68 & 74.24 & 5048 \\
\hline & Control & 60 & 53.47 & 3208 \\
\hline
\end{tabular}

The average range and the sum of ranges for the experimental group on the pretest and posttest are greater than for the control group. In order to determine whether there were significant differences, we proceeded to obtain the contrast statistics. This analysis for the pretest and posttest between the experimental group and the control group was carried out using the MannWhitney $\mathrm{U}$ test, the Wilcoxon $\mathrm{W}$ and the $\mathrm{Z}$ factor (see Table 6).

Table 6. Contrast Statistics between the experimental group and the control group

\begin{tabular}{lllll}
\hline & Mann-Whitney U test & Wilcoxon W & Z & Sig. \\
\hline Pretest & 1838 & 3668 & -1.005 & 0.315 \\
Posttest & 1378 & 3208 & -3.177 & 0.001 \\
\hline
\end{tabular}

On the pretest the significance is greater than 0.05 and therefore it may be established that there is equality between the experimental group and the control group. This means that there is no difference in academic performance. On the posttest the significance is less than 0.05 which indicates that there are differences between the experimental group and the control group. The sum of ranges and average range of the experimental group is greater than for the control group and therefore, the academic performance was greater in a Virtual Learning Environment.

\section{Conclusions}

Two research questions were posed and based on these we built the present study. The first objective consisted of determining the effect implementing a virtual learning environment would have on the index of failing in learning mathematics in a study group with respect to a group learning math using traditional education.

The percentage of students who failed was $23.24 \%$ less in the group of students using the proposed method. This answers the first research question. The decrease in the index of failing was significant based on the statistical test carried out and therefore the null hypothesis which expressed that the virtual learning environment of the linear model does not decrease the failure index was rejected. Therefore it may be affirmed that the virtual learning environment of the linear model does diminish the failure index.

The second objective was to determine the effect the implementation of a virtual learning environment for learning mathematics would have on a study group with respect to a group learning mathematics with traditional learning. In order to comply with this objective both intra- and inter-group statistical analysis were carried out.

Intra-group performance improved significantly for the students in the traditional class and also for the students in the group for which a virtual 
learning environment was implemented, according to statistical tests. Upon comparing inter-groups it was determined that the experimental group had better performance than the control group with 0.001significance. This evidence allows us to reject the null hypothesis which states that the virtual learning environment of the linear model does not improve academic performance and therefore it may be established that the virtual learning environment of the linear model does improve academic performance significantly and with this we answer the second research question.

The conclusions of this study coincide with those expressed by Bulman and Fairlie (2016) who found that instruction aided by ICT is positive in interventions in the area of mathematics and in developing countries, such as Mexico. Moreover, Hattie and Yates (2013) identified that ICT was more efficient, benefiting academic performance when used to broaden the time and practice of activities and also when interaction with the computer gave the student more freedom for controlling their learning progress.

Every day students have more possibilities of appropriating their own development in an environment where learning is conceived as a current with many resources and opportunities (Childress, 2016). Constant up-dating of VLE as well as ICT as pedagogical approaches will be what turns virtual learning into an option.

\section{Disclosure statement}

No potential conflict of interest was reported by the authors.

\section{References}

Bain, A., \& Weston, M. (2012). The Learning Edge. What technology can do to educate all children. New York: Teachers College Press.

Bravo, M. (2012). Capítulo 10. Enseñanza-aprendizaje de las matemáticas utilizando como apoyo ambientes virtuales de aprendizaje. In Y. Sandoval, A. Arenas, E. López, J. Cabero y J. Aguaded (Coords.), Las tecnologías de la información en contextos educativos: nuevos escenarios de aprendizaje (pp. 177-202). Columbia: Universidad Santiago de Cali.

Bulman, G., \& Fairlie, R. W. (2016). Chapter 5. Technology and Education: Computers, Software, and the Internet. In E. A. Hanushek, S. J. Machin y L. Woessmann (Eds.), Handbook of the Economics of Education. Volume 5 (pp. 239-280). Amsterdam: Elsevier.

Cabero, J. (2013). El aprendizaje autorregulado como marco teórico para la aplicación educativa de las comunidades virtuales y los entornos personales de aprendizaje. Revista Teoría de la Educación: Educación y Cultura en la Sociedad de la Información, 14(2), 133-156.

Cabero, J., \& Llorente, M. del C. (2006). La rosa de los vientos: Dominios tecnológicos de las TIC's por los estudiantes. Sevilla, España: Editorial Marquet@.

Childress, M. (2016). 29. Utopian Futures for Learning Technologies. In N. Rushby and D. W. Surry (Eds.), The Wiley Handbook of Learning Technology (pp. 557-570). Hoboken, New Jersey: John Wiley \& Sons, Inc.

Clark, R., \& Mayer, R. (2016). E-Learning and the Science of Instruction: Proven Guidelines for Consumers and Designers of Multimedia Learning. Hoboken, New Jersey: John Wiley \& Sons, Inc.

European Commission (2016). A New Skills Agenda for Europe. Working together to strengthen human capital, employability and competitiveness. Communication from the commission to the European parliament, the council, the European economic and social committee and the committee of the regions. Recovered from: http://ec.europa.eu/social/main.jsp?catId=1223 
Fullan, M., \& Langworthy, M. (2013). Towards a New End: New Pedagogies for Deep Learning. Seattle: Collaborative Impact.

Hattie, J., \& Yates, G. (2013). Visible Learning and the Science of How We Learn. United Kingdom: Routledge.

Khan, B. H. (2016). Revolutionizing Modern Education through Meaningful E-Learning Implementatiton. Hershey PA, USA: IGI Global.

OCDE (2016). Resultados de PISA 2015. Nota país. México. Recovered from: https://www.oecd.org/pisa/PISA-2015-Mexico-ESP.pdf

OCDE (2017). Acerca de la Organización para la Cooperación y el Desarrollo Económicos (OCDE). Recovered from: http://www.oecd.org/centrodemexico/laocde/

Onrubia, J. (2016). Aprender y enseñar en entornos virtuales: actividad conjunta, ayuda pedagógica y construcción del conocimiento. RED Revista de Educación a Distancia, 50(3), 1-14.

PISA (2017). Programme for International Student Assessment. PISA en español. Recovered from: https://www.oecd.org/pisa/pisaenespaol.htm

PLANEA (2016). Publicación de Resultados 2016. Recovered from: http://planea.sep.gob.mx/content/general/docs/2016/DifusionPLANEA_EMS.pdf

PLANEA (2017). Plan Nacional para la Evaluación de los Aprendizajes. Recovered from: http://www.planea.sep.gob.mx/

Salinas, P., Alanís, J., Pulido, R., Santos, F., Escobedo, J., \& Garza, J. (2012). Cálculo Aplicado. Competencias matemáticas a través de contextos. Tomo I. D.F., México: Cengage Learning Editores.

Silva, J. (2011). Diseño y moderación de entornos virtuales de aprendizaje (EVA). Barcelona, España: Editorial UOC.

Zakaria, N. A., \& Khalid, F. (2016). The Benefits and Constraints of the Use of Information and Communication Technology (ICT) in Teaching Mathematics. Creative Education, 7, 15371544 . 